\title{
Hyperprolactinemia after laparoscopic ovarian drilling: An
} unknown phenomenon

\author{
Mohammad E Parsanezhad*1, Saeed Alborzi ${ }^{1}$, Jaleh Zolghadri1 ${ }^{1}$, \\ Maryam Parsa-Nezhad ${ }^{2}$, Gholamreza Keshavarzi ${ }^{3}$, \\ Gholamhossein R Omrani ${ }^{4}$ and Ernst H Schmidt ${ }^{5}$
}

\begin{abstract}
Address: ${ }^{1}$ Division of infertility and GYN endocrinology, Department of Obstetrics and Gynecology, Medical School, Shiraz University of Medical sciences, Shiraz, Iran, 2Division of cell and Molecular Biology Department of biology, Shiraz University, Shiraz, Iran, ${ }^{3}$ Shiraz Health Network, Shiraz, Iran, ${ }^{4}$ Endocrine and Metabolism Research Centre, Nemazee Hospital, Medical school, Shiraz, University of Medical sciences, Shiraz, Iran and ${ }^{5}$ Division of infertility and GYN endocrinology, Department of Obstetrics and Gynecology, Evang. Diakonie Teaching Hospital of the Göttingen University, Bremen, Germany
\end{abstract}

Email: Mohammad E Parsanezhad* - parsame@sums.ac.ir; Saeed Alborzi - alborzis@sums.ac.ir; Jaleh Zolghadri1 - zolghadj@sums.ac.ir; Maryam Parsa-Nezhad - maryam_3_m@yahoo.com; Gholamreza Keshavarzi - parsanezhad@msn.com;

Gholamhossein R Omrani - Omranigh@sums.ac.ir; Ernst H Schmidt - frauenklinik@diako-bremen.de

* Corresponding author

Published: 07 August 2005

Reproductive Biology and Endocrinology 2005, 3:31 doi:10.1186/1477-7827-331

This article is available from: http://www.rbej.com/content/3/I/3I

(c) 2005 Parsanezhad et al; licensee BioMed Central Ltd.

This is an Open Access article distributed under the terms of the Creative Commons Attribution License (http://creativecommons.org/licenses/by/2.0), which permits unrestricted use, distribution, and reproduction in any medium, provided the original work is properly cited.
Received: 30 March 2005

Accepted: 07 August 2005

\begin{abstract}
Background: The effects of ovarian drilling on the serum levels of gonadotropins and androgens have been studied previously. The aim of this study is to evaluate the effects of ovarian drilling on the serum prolactin levels and its relation to ovulation in women with polycystic ovary syndrome.
\end{abstract}

Methods: This is a prospective controlled study. Thirty-six women with PCOS underwent ovarian electrocauterization in university hospitals. Control group consisted of 35 ovulatory women with unexplained infertility. Hormonal assessment performed in early follicular phase of spontaneous or induced cycle before operation in the two groups and repeated one week after operation. Hormonal assay was also performed in the early follicular phase of the first post-operative menstruation, folliculometry and progesterone assay were also performed in the same cycle. Data were analyzed by "repeated measurement design, discriminant analysis, correlation coefficient, and Fisher exact test".

Results: Six to ten weeks after operation the serum mean $+/$ - SD prolactin levels increased from $284.4 \mathrm{I}+/-$ I $14.32 \mathrm{mlU} / \mathrm{ml}$ to $354.06+/-204.42 \mathrm{mlU} / \mathrm{ml}(P=0.01 \mathrm{I})$. The same values for the control group were $277.73+/-$ II 4.65 to $277.4+/$ - II I.4 (P = 0.98 I) respectively. Approximately $45 \%$ of subjects in PCOS group remained anovulatory in spite of decreased level of $\mathrm{LH}$ and testosterone. Prolactin level remained elevated in $73.2 \%$ of women who did not ovulate $6-10$ weeks after the procedure.

Conclusion: Hyperprolactinemia after ovarian cauterization may be considered as a possible cause of anovulation in women with polycystic ovaries and improved gonadotropin and androgen levels. The cause of hyperprolactinemia is unknown. Hormonal assay particularly PRL in anovulatory patients after ovarian cauterization is recommended. 


\section{Background}

The polycystic ovary syndrome (PCOS) is associated with chronic anovulation and infertility. In most cases ovulation can be induced with clomiphene citrate (CC) but approximately $25 \%$ of patients fail to ovulate and require alternative treatment [1]. Human menopausal gonadotropins have been used but the risk of hyperstimulation and multifetal gestation [2]. A variety of surgical options for the treatment of PCOS have been applied during laparoscopy (biopsy, cauterization, laser surgery)[3]. Laparoscopic ovarian drilling (LOD) was first described by Gjonnaess [4]. The reported ovulation rate after LOD varies between $50 \%$ and $90 \%$ [4-7], the conception rate dose not increase in parallel with the increase in ovulation rate. There is also some disparity between hormonal improvement and ovulation rate [7-9]. Part of disparity may be due to post-operative adhesion formation [10], post-LOD hyperprolactinemia [11], and any unknown reason. Although many studies concerning the endocrine effects of LOD have been performed [12-16], none has emphasized on the cause of disparity between hormonal changes and ovulation. We performed this prospective, controlled study to evaluate the effects of LOD on hormonal profile particularly prolactin and their possible effects on ovulation.

\section{Materials and methods}

This study was performed in the Division of Infertility and Gynecologic Endocrinology, Shiraz University of Medical Sciences, Shiraz Iran. Between January 1998 and November 2003, 102 women with PCOD were recruited but 60 of them were not eligible and excluded. Thus 42 clomiphene-citrate resistant anovulatory women with PCOS were enrolled into this prospective, controlled study. Before laparoscopic ovarian drilling, these women had failed to ovulate with the maximum dose of CC $(200 \mathrm{mg} /$ day for 5 days for at least 5 cycles). Polycystic ovary syndrome was diagnosed on the basis of the following criteria: hirsutism, menstrual disturbances (oligo- or amenorrhea), increased plasma circulating androgens, LH/FSH ratio $>2.5$, and typical ultrasonographic findings [17]. We excluded all women with PRL level >500 MIU/ $\mathrm{ml}$.

The control series consisted of thirty-five unexplained infertility that had ovulatory cycles and had been referred for diagnostic laparoscopy. At a minimum, the diagnosis of unexplained infertility implies a normal semenanalysis, objective evidence of ovulation, a normal uterine cavity, bilateral tubal patency, and normal post-coital test. They were chosen because the diagnostic laparoscopy procedure utilized was very similar to the LOD in terms of premedication and anesthesia. Ethic committee for Human Research of the university approved the study and informed consent was taken from each patient. In all patients baseline blood samples were obtained before operation (2-3 days after the commencement of spontaneous or progesterone induced menstrual bleeding) to assess serum levels of LH, FSH, PRL, DHEAS and T. First post-operative blood sample was taken 24 hours after operation. Second sampling was performed one week after LOD, and the third blood sample obtained in the early follicular phase of first post-operative menstrual cycle (approximately 6-10 weeks after operation). If menstruation did not occur till one month after LOD, $100 \mathrm{mg}$ of progesterone would be administered intramuscularly to stimulate menstruation. This cycle was monitored for ovulation using serum progesterone $(\mathrm{P})$ measurement in the mid-luteal phase and folliculometry that was performed on days 14-16 of the first menstrual cycle after operation. The samples were labeled; serum was separated and frozen until the end of study when all of them were assayed by the same kit of radioimmunoassay (RIA). PRL was measured in plasma pool (3 samples separated by 30 minute intervals). Women with PCOS (Group A) were treated with laparoscopic ovarian drilling. Laparoscopic ovarian drilling was performed using two-puncture technique. We used an optic that equipped with operative channel. The laparoscope was introduced through a subumblical incision and a grasping forceps was introduced suprapubically to stabilize the ovary by grasping the ovarian ligament. After assessment of the pelvic structures and tubal patency, an insulated needle connected to a unipolar electrocautery unit was inserted through operative channel of the optic. Eight to ten cautery points 3-4 mm in diameter was created in each ovary with a current of 4 $\mathrm{mA}$ applied through the laparoscopic insulated needle. Control group (Group B) underwent diagnostic laparoscopy as standard double puncture method under general anesthesia by the same surgeons and anesthetists.

\section{Statistical methods}

Pre-operative and post-operative clinical and endocrinologic parameters in various sessions were compared using "repeated measurement design (Bonferroni test"). Fisher exact test was used to determine progesterone changes and menstruation in the two groups after procedure. We also used "discriminant analysis" for ovulation as dependent factor and other study parameters. Correlation of prolactin levels with ovulation was compared using "correlation coefficient test".

\section{Normal values of hormonal levels}

FSH $=3-13 \mathrm{mIU} / \mathrm{ml}, \mathrm{LH}=1.5-12 \mathrm{mIU} / \mathrm{ml}$, Testosterone $=0.2-0.9 \mathrm{ng} / \mathrm{ml}$, DHEAS $=80-350 \mathrm{microgram} / \mathrm{dl}$, Prolac tin $=50-450 \mathrm{mIU} / \mathrm{ml}$.

\section{Results}

Of a total of forty-two PCOS women enrolled, 36 completed the study protocol, 6 lost to follow up and were 
Table I: Hormonal profile(Mean +/-SD) at baseline and various sessions after operation in PCOS and control group (All post operative sessions compared with baseline).

\begin{tabular}{|c|c|c|c|c|}
\hline & 0 & I(P.Value) & 2(P.Value) & 3(P.Value) \\
\hline \multicolumn{5}{|l|}{ I-FSH } \\
\hline PCOS & $6.4+/-1.97$ & $6.21+/-I .7 I(0.904)$ & $6.35+/-1.68(0.616)$ & $6.17+/-1.62(0.812)$ \\
\hline Control & $6.74+/-1.75$ & $6.81+/-1.39(0.782)$ & $6.58+/-1.79(0.417)$ & $6.47+/-1.24(0.407)$ \\
\hline \multicolumn{5}{|l|}{ 2-LH } \\
\hline PCOS & $|6.2|+|-4.4|$ & $\mid 4.28+/-4.04(0.00 \mid)^{*}$ & $13.95+/-3.54(0.001)^{*}$ & $8.26+/-2.17(0.001)^{*}$ \\
\hline Control & $8.02+|-| .3 \mid$ & $8.32+/-1.68(0.356)$ & $8.31+/-1.98(0.403)$ & $7.78+/-1.49(0.470)$ \\
\hline \multicolumn{5}{|l|}{ 3-LH/FSH R } \\
\hline PCOS & $2.7 \mid+/-0.58$ & $2.36+/-0.59(0.002)^{*}$ & $2.3+/-0.7(0.00 \mathrm{I})^{*}$ & $1.42+/-0.47(0.001)^{*}$ \\
\hline Control & $1.23+/-0.22$ & $1.23+/-0.13(0.961)$ & $1.28+/-0.13(0.295)$ & $1.22+/-0.23(0.897)$ \\
\hline \multicolumn{5}{|l|}{ 4-DHEA, S } \\
\hline PCOS & $201.14+/-103.21$ & $199.5+/-98.92(0.772)$ & $195.17+/-9043(0.538)$ & 199.56+/-95.I(0.794) \\
\hline Control & $198.37+/-82.66$ & $186.77+/-73.75(0.262)$ & $187.2+/-79.97(0.157)$ & $191.17+1-68.04(0.306)$ \\
\hline \multicolumn{5}{|l|}{$5-T$} \\
\hline PCOS & $1.18+/-0.33$ & $1.12+/-0.31(0.008)^{*}$ & $1.08+/-0.28(0.001)^{*}$ & $0.78+/-0.25(0.001)^{*}$ \\
\hline Control & $0.66+/-0.23$ & $0.54+/-0.22(0.004)^{*}$ & $0.61+/-0.17(0.095)$ & $0.62+/-0.17(0.081)$ \\
\hline \multicolumn{5}{|l|}{ 6-PRL } \\
\hline PCOS & $284.4|+/-| 14.32$ & $651.83+/-316.79(0.001)^{*}$ & $530.31+/-206.74(0.001)^{*}$ & $354.06+/-204.42(0.011)^{*}$ \\
\hline Control & $277.73+/-114.65$ & $732.23+/-209.91(0.001)^{*}$ & $512.7+/-131.1(0.001)^{*}$ & $277.4+/-111.4(0.981)$ \\
\hline \multicolumn{5}{|l|}{ 7-Prog } \\
\hline PCOS & - & - & - & $5.99+/-3.68$ \\
\hline Control & - & - & - & $8.58+/-2.31$ \\
\hline
\end{tabular}

$0=$ Baseline

$\mathrm{I}=$ Mean $+/$-SD $24 \mathrm{~h}$ after operation

$2=$ Mean $+/$-SD one week after operation

$3=$ Mean $+/$ SD $6-10$ weeks after operation

$*=$ significant $\mathrm{P}$ value $(\mathrm{P}<0.05)$

Table 2: Comparison of study parameters in PCOS group. Women who ovulated spontaneously Vs. women who did nor ovulated spontaneously.

\begin{tabular}{llll}
\hline & Anovulatory group & Ovulatory group & P value \\
\hline I-Age & $24.31+/-3.6$ & $23.95+/-2.92$ & 0.74 \\
2-FSH & $5.91+/-1.95$ & $6.37+/-1.31$ & 0.4 \\
3-LH & $8.06+/-1.99$ & $8.42+/-2.33$ & 0.63 \\
4-DHEAS & $209.125+/-96.033$ & $191.9+/-96.13$ & 0.59 \\
5-T & $0.75+/-0.26$ & $0.8+/-0.24$ & 0.52 \\
6-PRL & $501.31+/-205.130$ & $236.25+/-104.34$ & $0.000^{*}$ \\
7-F. Size & $9.45+/-1.48$ & $17.1+/-1.33$ & $0.000^{*}$
\end{tabular}

excluded. We also excluded five women in control group who did not complete the measurements. Ultimately, 36 women in PCOS group and 30 women in control group underwent final analysis. Mean age in PCOS and control groups were $24.11+/-3.22$ (range 19 to 31 ) and $24.5+/$ 3.95(range 19 to 32 ) respectively. Typical endocrine profiles of baseline, and after operation (24 hours, one week and 6-10 weeks) of the two groups are shown in (Table 1). After operation, PRL levels in the both groups increased significantly at 24 hours $(\mathrm{P}<0.001)$ while the other hormonal profiles showed no such changes. Serum levels of LH $(\mathrm{P}<0.001)$, T $(\mathrm{P}<0.001)$, and also LH/FSH ratio $(\mathrm{P}<0.001)$ decreased to a statistically significant level 6-10 weeks after operation. Comparison of study parameters in PCOS group: women who ovulated spontaneously Vs. women who did not ovulated spontaneously, showed that prolactin levels were significantly higher in anovulatory group and follicle size (F.Size) is grater in ovulatory group (Table 2). Hormonal profiles at baseline and all sessions after operation between PCOS and control group were compared. The results are depicted in Table 3. Twenty-four hours after operation serum PRL lev- 
Table 3: Comparison hormonal profiles(Mean+/-SD) at baseline and various sessions after operation, between PCOS \& control group.

\begin{tabular}{|c|c|c|c|c|}
\hline & 0 ( $P$ value $)$ & $I(P$ value $)$ & 2 ( $p$ value) & 3 ( $p$ value) \\
\hline \multicolumn{5}{|l|}{ I-FSH } \\
\hline PCOS & $6.4+/-1.97(0.27)$ & $6.21+/-1.71(0.13 \mid)$ & $6.35+/-1.68(0.555)$ & $6.17+/-1.62(0.31)$ \\
\hline Control & $6.74+/-1.75$ & $6.81+/-1.39$ & $6.58+/-1.79$ & $6.47+/-1.24$ \\
\hline \multicolumn{5}{|l|}{ 2-LH } \\
\hline PCOS & $|6.2|+|-4.4|(<0.001)^{*}$ & $|4.28+|-4.04(<0.00 \mid) *$ & $13.95+/-3.54(<0.001) *$ & $8.26+/-2.17(0.24)$ \\
\hline Control & $8.02+/-1.31$ & $8.32+/-1.68$ & $8.31+/-1.98$ & $7.78+/-1.49$ \\
\hline \multicolumn{5}{|l|}{ 3-DHEAS } \\
\hline PCOS & $201.14+/-103.2(0.906)$ & $199.5+/-98.92(0.562)$ & $195.17+/-90.43(0.699)$ & $199.56+/-95.1(0.029)$ \\
\hline Control & $198.37+/-82.66$ & $186.77+/-73.75$ & $187.2+/-79.97$ & $191.17+/-68.04$ \\
\hline \multicolumn{5}{|l|}{ 4- $T$} \\
\hline PCOS & $1.18+/-0.33(0.001) *$ & $1.12+/-0.31(<0.001) *$ & $1.08+/-0.28(<0.001) *$ & $0.78+/-0.25(0.1)$ \\
\hline Control & $0.66+/-0.23$ & $0.54+/-0.22$ & $0.61+/-0.17$ & $0.62+/-0.17$ \\
\hline \multicolumn{5}{|l|}{ 5-PRL } \\
\hline PCOS & $284.4 I+/-I \mid 4.32(0.8 \mid 4)$ & $651.83+/-316.76(0.239)$ & $530.31+/-206.74(0.688)$ & $354.06+/-204.42(0.006)^{*}$ \\
\hline Control & $277.73+/-1 \mid 4.65$ & $732.23+/-209.9$ & $5|2.7+/-13| . \mid$ & $277.4+/-111.4$ \\
\hline
\end{tabular}

0 = Baseline

$=$ Mean $+/-$ SD $24 \mathrm{~h}$ after operation

$2=$ Mean $+/-S D$ one week after operation

$3=$ Mean $+/-S D 6-10$ weeks after operation $*=$ significant $P$ value $(P<0.05)$

Table 4: Clinical and hormonal outcome 6-10 weeks after operation in the two groups.

\begin{tabular}{|c|c|c|c|c|}
\hline & NOPW L.F> I 5 mm (\%) & $\begin{array}{r}\text { NOPW Prog }>5 \text { ng/ml } \\
(\%)\end{array}$ & NOPW S.M (\%) & NOPW E. PRL (\%) \\
\hline I-PCOS & $19(52.8)$ & $20(55.6)^{*}$ & $20(55.6)^{*}$ & $10(27.8)^{*}$ \\
\hline 2-Control & $21(70)$ & $30(100)$ & $30(100)$ & 2.(6.7\%) \\
\hline
\end{tabular}

* = significant $\mathrm{P}$ Value

Differences compared with pre-operation value

NOPW L.F $=$ Number of Patients With Leading Follicle.

NOPW Prog $=$ Number of Patients With Progesterone

NOWP S.M = Number of Patients With Spontaneous Menstruation.

NOPW E. PRL = Number of Patients With Elevated Prolactin.

els rose in $88.9 \%$ of PCOS and $100 \%$ of control group respectively (Table 1). Serum PRL levels remained elevated $6-10$ weeks after operation in $27.8 \%$ of PCOS $(\mathrm{P}<$ $0.05)$ and $6.7 \%$ of control group $(\mathrm{P}>0.05)$ (Table 4$)$. After operation, $20(55.6 \%)$ of PCOS and $30(100 \%)$ of control group ovulated as indicated by midluteal serum progesterone level $>5 \mathrm{ng} / \mathrm{ml}$, spontaneous menstruation and leading follicular size $>15 \mathrm{~mm}$ (Table 4 ). Of all patients that remained anovulatory in spite of decrease in $\mathrm{LH}$ and $\mathrm{T}$ after LEC, PRL remained higher than normal limits in $62.5 \%$.

\section{Discussion}

This is the first prospective, controlled study on the PRL level after LOD Vs. diagnostic laparoscopy. Our study shows that laparoscopic ovarian drilling can restore ovu- lation in some but not all PCOS women. This confirms the results from previous studies [4-7]. Kovacs et al [12] in their recent study of comparison of ovulation and pregnancy rate has found no difference in success rates between ovarian drilling and gonadotropin ovulation induction for such women in spite of hormonal improvement after LOD. Abdel Ghadir et al [7] also reported that beside its favorable endocrine effects, ovarian drilling revealed the same rate of ovulation and pregnancy in comparison with HMG induced cycle. In the present study we were able to show that with ovarian drilling, T and LH levels decreased irrespective of ovulation. $\mathrm{LH}$ and T decreased in $75 \%$ and $70 \%$ of PCOS patients respectively, whereas only $52.8 \%$ of women who underwent ovarian drilling ovulated. Periovarian adhesion after ovarian electrocautery seems to be the main cause of disparity 
between ovulation and pregnancy rate. Many authors believe that although periovarian adhesion after ovarian drilling is much less when compared with ovarian wedge resection, still some significant adnexal adhesion that adversely affects fertility may be considered [10,18,19]. The unanswered question concerning the effects of ovarian drilling is the disparity between favorable endocrine effects of this procedure and ovulation rate. Concerning the endocrine effects of LOD, Gjonness et al [20] in their study on 17 women showed a transient hyperprolactinemia immediately after LOD. They believed that this phenomenon was due to operative stress. Eldib et al in their unpublished study on 20 women with PCOS showed that LOD was associated with increased PRL levels by 7 folds two weeks after operation.

We hypothesized that the disparity seen between hormonal improvement and ovulation rate might be due to the hyperprolactinemia associated LOD. Of all operated women that remained anovulatory in spite of significant fall in LH and T levels, PRL remained elevated in $62.5 \%$ when measured 6-10 weeks after operation. Serum prolactin level began to rise from the first day after LOD in the two groups. Six to ten weeks after operation, PRL level in the women with PCOS was significantly higher than control group. Hyperprolactinemia as a complication of operation, and/or anesthesia was previously described by Adashi [21], Chan [22], Frantz [23], Newsome [24], Charters [25], and Soules et al [26]. An elevated PRL level was common finding during and after operation with the peak PRL levels always occurring during surgery. The elevated post-operative PRL levels may be explained by a generalized stress reaction (e.g., pain) and by medications known to stimulate PRL release (e.g., narcotics) [27]. We did not measure PRL intra-operatively, but post-operative elevated levels of PRL support the results of previous studies. Noel et al [28] and Sowers [29] reported an acute increase in PRL concentration with the induction of anesthesia prior to the operative incision. The operative increase in PRL was greater in women than in men and persisted for a various periods [28]. The post-operative elevated PRL levels improved spontaneously after a maximum period of one week. Approximately all subjects in the two groups and the most cases of PCOS had normal PRL 6-10 weeks after LOD. A large number of women with PCOS, who remained anovulatory after LOD, had still elevated serum PRL levels. Gjonnaess in his study of long term follow up showed no difference between baseline PRL levels and PRL levels after 3 months or later after LOD [30]. The disparity between this study and our results may be due to the longer duration between LOD and PRL assay in Gjonnaess group. Since the LOD and control group were in the same condition concerning the surgical and anesthesiologic stress, and the post-operation elevated PRL level was supposed to decrease after one week, the elevated PRL lev- els 6-10 weeks after operation in LOD group may be due to other cause than surgical or anesthesiologic stress. The mechanism for the increase in PRL levels after LOD remains speculative. The possible mechanism might be scar formation on the surface of ovaries and chronic stimulation of ovarian nerves and causing neurogenic hyperprolactinemia, like chest wall lesion, intercourse or spinal cord lesions. For documentation of this hypothesis animal models should be designed.

In this prospective controlled study control group helped us to differentiate stress-induced hyperprolactinemia from the hyperprolactinemia associated with LOD. The weak point of this preliminary report is that the hormonal assay was performed in early and late post-operative phase. More exact hormonal study is necessary to evaluate the condition. However this study provides a potential new way to evaluate the factors that affecting ovulation rate after LOD including hyperprolactinemia. It seems that animal study to evaluate the relationship between ovarian damage and PRL levels would be helpful. Increase in serum PRL levels associated with LOD has several implications in clinical practice; 1- post-operative elevated PRL levels affects gonadotropins and ovarian steroidogenesis $[31,32]$, so it would be prudent not to rely on early hormonal profiles after LOD, 2- Since the latent hyperprolactinemia may lead to luteal phase defect [33] if the first cycle after LOD was ovulatory, luteal phase defect must be considered and treated. 3- If ovulation did not occurred as expected, diagnosis and treatment of hyperprolactinemia should be undertaken.

\section{Conclusion}

We conclude that after ovarian drilling, women who remained anovulatory in spite of decreased serum androgen levels and other hormonal profile improvement, may have elevated prolactin levels. The cause of hyperprolactinemia in these patients has not known. Hormonal assay particularly PRL in anovulatory patients after LOD is recommended. Animal study to evaluate the relationship between ovarian damage and PRL levels would be helpful

\section{Authors' contributions}

M.E.Parsanezhad,. Conception and design, Lapascopies.

S. Alborzi, Conception and design of the study and referring patients to our clinic.

Jaleh Zolghadri. Conception and design, coordination and helped to draft the manuscript.

Maryam Parsa-Nezhad. Carried out the hormonal assays, participated in the sequence alignment.

Gh.Keshavarzi. Carried out the hormonal assays. 


\section{GH R.Omrani. Carried out the hormonal assays.}

E.H.Schmidt. He has been involved in revising the manuscript.

\section{References}

I. Franks S, Mason HD, Polson DW, Winstpon RML, Margara R, Reed $\mathrm{MJ}$ : The mechanism and management of ovulatory failure in women with polycystic ovary syndrome. Hum Reprod 1988, 3:43I-434.

2. Rabe T, Diedrich K, Runnebaum B: Manual on assisted reproduction. Berlin: Springer; 1997: I54.

3. Cohen J: Laparoscopic procedures for treatment of infertility related to polycystic ovary syndrome. Hum Reprod Update 1996, 2:337-344.

4. Gjonnaess H: Polycystic ovarian syndrome treated by ovarian electrocautery through the laparoscope. Fertil Steril 1984, 4I:20-25.

5. Daniel JF, Miller W: Polycystic ovaries treated by laparoscopic laser vaporization. Fertility and Sterility 1989, 5 I:232-236.

6. Armar NA, Mc Carrigle HHG, Honour J, Holownia P, Jacobs HS, Lachelin GCL: Laparoscopic ovarian diathermyin the management of anovulatory infertility in women with polycystic ovaries: endocrinic changes and clinical outcome. Fertility and Sterility 1990, 53:45-49.

7. Abdel Ghadir A, Khatim MS, Mowafi RS, Alnaser HMI, Alzaid HGN, Shaw RW: Ovarian electrocautery versus human menopausal gonadotropins and pure follicle stimulatin hormone therapy in the treatment of the patients with polycystic ovarian disease. Clinical Endocriniology 1990, 33:585-592.

8. Abdel Ghadir A, Khatim MS, Mowafi RS, Alnaser HMI, Shaw RW: Endocrine changes following ovarian electrocautery in patients with polycystic ovarian syndrome. In Advances in reproductive endocrinology Edited by: Shaw RW. Carnforth: Parthenon Publishing Group Ltd; 1991:135.

9. Balen $\mathrm{AH}$, Jacobs $\mathrm{HS}$ : A prospective study comparing unilateral and bilateral laparoscopic ovarian diathermy in women with the polycystic ovary syndrome. Fertil Steril 1994, 62:92I-925.

10. Gurgan T, Kisnisci H, Yarali H, Develioglu O, Zeyneloglu H, Aksu T: Evaluation of adhesion formation after laparoscopic treatment of polycystic ovarian disease. Ferti Steril 56: I I 76- I 178.

II. Kovacs GT, Clarke S, Burger HG, Healy DL, Vollenhoven B: Surgical or medical treatment of polycystic ovary syndrome: a costbenefit analysis. Gynecol Endocrinol 2002, 16:53-55.

12. Alborzi S, Khodaee R, Parsanejad ME: Ovarian size and response to laparoscopic ovarian electro-cauterization in polycystic ovarian disease. Int / Gynaecol Obstet 200I, 74:269-274.

13. Vicino M, Loverro G, Bettocchi S, Simonetti S, Mei L, Selvaggi L: Predictive value of serum androstenedione basal levels on the choice of gonadotropin or laparoscopic ovarian electrocautery as ovulation induction in clomiphene citrate-resistant patients with polycystic ovary syndrome. Gynecol Endocrinol 2000, 14:42-49.

14. Taskin O, Yalcinoglu Al, Kafkasli A, Burak F, Ozekici U: Comparison of the effects of ovarian cauterization and gonadotropin releasing hormone agonist and oral contraceptive therapy combination on endocrine changes in women with polycystic ovarian disease. Fertil Steril 1996, 65: I I I5-1 I I8.

15. Gjonnaess H: Late endocrine effects of ovarian electrocautery in women with polycystic ovary syndrome. Ferti Steril 1998, 69:697-70I.

16. Insler V, Lunenfeld B: Polycystic ovarian disease: a challenge and controversy. Gynecol Endocrinol 1990, 5:5 I-69.

17. The Rotterdam ESHRE/ASRM-Sponsored PCOS Consensus Workshop Group. Revised 2003 consensus on diagnostic criteria and long-term health risks related to polycystic ovary syndrome. Fertil Steril 2004, 8I: 19-25.

18. Naether OGJ, Fischer R, Weise HC, Geiger-Kutzler L, Delfs T, Rudolf $\mathrm{K}$ : Laparoscopic electrocoagulation of the ovarian surface in infertile patients with polycystic ovarian disease. Fertil Steril 1993, 60:88-94.

19. Naether OG], Fischer R: Adhesion formation after laparoscopic electrocoagulation of the ovarian surface in polycystic ovary patients. Fertil Steril 1993, 60:95-98.
20. Gjonnaess H, Norman : Endocrine effects of ovarian electrocautery in patients with polycystic ovarian disease. $\mathrm{Br} J$ Obstet Gynaecol 1987, 94:779-783.

21. Adashi EY, Rebar RW, Ehara Y, Naftolin F, Yen SSC: Impact of acute surgical stress on anterior pituitary function in female subjects. Am J Obstet Gynecol 1980, I38:609-6I4.

22. Glick SM, Roth J, Yalow RS: The regulation of growth hormone secretion, Recent Prog. Horm Res 1965, 21:241-244.

23. Frantz AG, Lienberg DL, Noel GL: Studies on prolactin in man. Recent Prog Horm Res 1972, 28:527-590.

24. Newsome HH, Rose JC: The response of human adrenocorticotrophic hormone and growth hormone to surgical stress. Clin Endocrinol Metab I97I, 33:48I-487.

25. Charters AC, Odell WD, Thompson JC: Anterior pituitary function during surgical stress and convalescence. Radioimmunoassay measurement of blood TSH, LH, FSH and growth hormone. J Clin Endocrinol Metab 1969, 29:63-7I.

26. Soules MR, Sutton GP, Hammond CB, Haney AF: Endocrine changes at operation under general anesthesia: Reproductive hormone flactuations in young women. Fertil Steril 1980, 33:364-37I.

27. Tolis G, Hickey J, Guyda H: Effects of morphine on serum growth hormone, cortisol, prolactin and thyrid stimulating hormone in man. J Clin Endocrinol Metab 1975, 41:797-800.

28. Noel GL, Suh HK, Stone JG, Frantz AG: Human prolactin and growth hormone release during surgery and other conditions of stress. Clin Endocrinol Metab 1972, 35:840-85I.

29. Sowers JR, Raj RP, Hershman JM, Carlson HE, McCallum RW: The effect of stressful diagnostic studies and surgery on anterior pituitary hormone release in man. Acta Endocrinol (Copenh) 1977, 86:25-32.

30. Gjonnaess A: Late endocrine effects of ovarian electrocautery in women with polycystic ovary syndrome. Fertil Steril 1998, 69(4):697-70I.

31. McNatty KP, Sawers RS, McNeilly AS: A possible role for prolactin in control of steroid secretion by the human Graafian follicle. Nature 1974, 23(250):653-655.

32. del Pozo E, Varga L, Schulz KD, Kunzig HJ, Marbach P, del Campo GL, Eppenberger U: Pituitary and ovarian response patterns to stimulation in the postpartum and in galactorrhea-amenorrhea. The role of prolactin. Obstet Gynecol 1975, 46:539-543.

33. Wuttke W, Pitzel L, Seidlova-Wuttke D, Hinney B: LH pulses and the corpus luteum: the luteal phase deficiency LPD). Vitam Horm 200I, 63:I3I-I58.

Publish with Bio Med Central and every scientist can read your work free of charge

"BioMed Central will be the most significant development for disseminating the results of biomedical research in our lifetime. "

Sir Paul Nurse, Cancer Research UK

Your research papers will be:

- available free of charge to the entire biomedical community

- peer reviewed and published immediately upon acceptance

- cited in PubMed and archived on PubMed Central

- yours - you keep the copyright
BioMedcentral 